\title{
Hemodilutional anemia impairs neurologic outcome after cardiopulmonary bypass in a piglet model
}

\author{
Takashi Miura, MD, ${ }^{\text {a }}$ Takahiko Sakamoto, MD, ${ }^{a}$ Makio Kobayashi, MD, ${ }^{b}$ Toshiharu Shin'oka, MD, and
} Hiromi Kurosawa, $\mathrm{MD}^{\mathrm{a}}$

From the Department of Cardiovascular Surgery, Heart Institute of Japan, ${ }^{\mathrm{a}}$ and Department of Pathology, Tokyo Women's Medical University, ${ }^{\mathrm{b}}$ Tokyo, Japan.

Received for publication Jan 1, 2006; revisions received Aug 12, 2006; accepted for publication Aug 28, 2006.

Address for reprints: Takashi Miura, MD, Department of Cardiovascular Surgery, The Heart Institute of Japan, Tokyo Women's Medical University, 8-1 Kawada-cho, Shinjuku-ku, Tokyo 162-8666, Japan (Email: takashiren@yahoo.co.jp).

J Thorac Cardiovasc Surg 2007;133:29-36 $0022-5223 / \$ 32.00$

Copyright $(92007$ by The American Association for Thoracic Surgery

doi:10.1016/j.jtcvs.2006.08.048
Objectives: The effect of hemodilution on neurologic outcome after cardiopulmonary bypass remains unclear. We studied the influences of hematocrit on cerebral oxygenation and neuropathologic outcome in a piglet model.

Methods: Eleven piglets $(9.3 \pm 1.1 \mathrm{~kg})$ were randomized into 2 groups. Five piglets (group $\mathrm{H})$ received a total blood prime resulting in a high hematocrit $(33.0 \% \pm$ $2.3 \%$ ), and 6 piglets (group L) received a crystalloid prime resulting in a low hematocrit $(14.0 \% \pm 3.2 \%)$. Both groups underwent 90 minutes of moderate hypothermic cardiopulmonary bypass $\left(28^{\circ} \mathrm{C}\right)$ with alpha-stat strategy. Cerebral oxygenation was monitored by near-infrared spectroscopy. Group L received a blood transfusion immediately after cardiopulmonary bypass to reach the postoperative target hematocrit of 30\%. The brain was fixed in situ 6 hours after weaning from cardiopulmonary bypass, and a histologic score for neurologic injury was assessed.

Results: There were no significant differences in arterial blood gas analyses throughout the experiment between the groups. Mean arterial pressure, mixed venous oxygen saturation, and heart rate were significantly higher in group $\mathrm{H}$ compared with group L during hypothermia. Oxyhemoglobin and total hemoglobin signals detected by near-infrared spectroscopy were significantly lower in group L (analysis of variance, $P<.0001$ ), although the tissue oxygenation index was not different during cardiopulmonary bypass. Group L showed a poorer histologic score compared with group $\mathrm{H}(P=.0071)$.

Conclusions: Excessive hemodilution, such as a hematocrit of less than $15 \%$, may be associated with a high incidence of neurologic injury. Further studies are required to determine the safety limits of hematocrit during pediatric cardiopulmonary bypass.

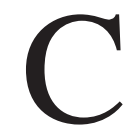
ardiopulmonary bypass $(\mathrm{CPB})$ has contributed to the improvement of cardiovascular surgery. In this regard, CPB without using homologous blood transfusion has become common in adult cardiac surgery in recent years and has been applied in pediatric cardiac surgery. The advantage of this method is that it protects patients against the risk of graft-versus-host disease and viral infections such as hepatitis. On the other hand, extreme hemodilution reduces the oxygencarrying capacity of blood and results in the impairments of systemic organs, particularly the brain. Recently, Jonas and colleagues ${ }^{1}$ reported the importance of a higher hematocrit during CPB with deep hypothermic circulatory arrest. It is also reported that a lower hematocrit is associated with poorer neurologic outcome and renal failure in adult cardiac surgery with continuous $\mathrm{CPB} .^{2}$ However, it is still unknown whether a higher hematocrit such as $30 \%$ is necessary for protecting the pediatric brain during continuous $\mathrm{CPB}$ without circulatory arrest. The aim of this study was to determine the effects of hemodilution under continuous CPB on cerebral function by using a neuromonitoring system such as near-infrared spectroscopy (NIRS) and histologic examination in a piglet model. 

Abbreviations and Acronyms
$\mathrm{CPB}=$ cardiopulmonary bypass
$\mathrm{CytO}_{2}=$ oxidized cytochrome $\mathrm{a}, \mathrm{a}_{3}$
$\mathrm{HbO}_{2}=$ oxygenated hemoglobin
$\mathrm{HbT}=$ total hemoglobin
$\mathrm{HHb}=$ deoxygenated hemoglobin
NIRS $=$ near-infrared spectroscopy
TOI = tissue oxygenation index

\section{Materials and Methods \\ Experimental Preparation}

Eleven 4- or 5-week-old Yorkshire piglets, weighing $9.3 \pm 1.1 \mathrm{~kg}$, were sedated with intramuscular ketamine $(20 \mathrm{mg} / \mathrm{kg})$ and intubated with 5-mm cuffed endotracheal tubes. Each animal was ventilated at a peak inspiratory volume of $10 \mathrm{~mL} / \mathrm{kg}$ at an inspired oxygen fraction of 0.21 and a rate of 12 to 18 breaths per minute by means of a volume-control ventilator (ACE-300; Acoma Corporation, Tokyo, Japan) to achieve a normal $\mathrm{pH}$ and arterial carbon dioxide tension. A pair of fiberoptic optodes for NIRS was placed on the head over the frontal lobes, with an interoptode distance of $4.0 \mathrm{~cm}$. Anesthesia was induced with an intravenous bolus injection of midazolam $(0.3 \mathrm{mg} / \mathrm{kg})$ and pancuronium $(0.5 \mathrm{mg} / \mathrm{kg})$, and maintained by continuous inhalation of sevoflurane $(0.8 \%-1.5 \%)$ and continuous infusion of midazolam $(0.2 \mathrm{mg} / \mathrm{kg} / \mathrm{h})$ and pancuronium $(0.2 \mathrm{mg} / \mathrm{kg} / \mathrm{h})$ throughout the experiment.

For the intraoperative monitoring and blood sampling, arterial and venous lines were placed in the left superficial femoral artery and right femoral vein, respectively. The right femoral artery was exposed for the $\mathrm{CPB}$ arterial cannula, and a right anterolateral thoracotomy was performed in the third intercostal space to expose the right atrium for venous cannulation. After systemic heparinization $(300 \mathrm{IU} / \mathrm{kg}$ ), an $8 \mathrm{~F}$ arterial cannula (Medtronic Bio-Medics, Minneapolis, Minn) and a $28 \mathrm{~F}$ venous cannula (Terumo Corporation, Tokyo, Japan) were inserted into the right femoral artery and right arterial appendage, respectively. All animals received humane care in compliance with the "Principles of Laboratory Animal Care," formulated by the National Society for Medical Research, and "Guide for the Care and Use of Laboratory Animals," prepared by the Institute of Laboratory Animal Resources, National Research Council and published by the National Academy Press, revised in 1996.

\section{Experimental Groups and Conditions}

Piglets were randomized into 2 groups. Group $\mathrm{H}(\mathrm{n}=5)$ received a total fresh blood prime resulting in a high hematocrit of approximately $30 \%$. Group L $(\mathrm{n}=6)$ received crystalloid priming resulting in a low hematocrit of less than $20 \%$. Operative conditions and intraoperative data were evaluated between the groups, and the relationship between the NIRS data and the neurologic outcome was examined comprehensively.

\section{Cardiopulmonary Bypass Technique}

The CPB circuit consisted of a roller-pump (Sarns 8000; Terumo Corporation, Tokyo, Japan) with a membrane oxygenator and sterile tubing (Capiox Rx 05; Terumo Corporation, Tokyo, Japan).
The prime was determined according to the experimental protocol. Group H was primed with $1200 \mathrm{~mL}$ of whole blood. Group L was primed with $900 \mathrm{~mL}$ of crystalloid solution, $200 \mathrm{~mL}$ of hydroxyethylated starch, and $50 \mathrm{~mL}$ of mannitol. Methylprednisolone (30 $\mathrm{mg} / \mathrm{kg})$, furosemide $(0.25 \mathrm{mg} / \mathrm{kg})$, sodium bicarbonate $(10$ $\mathrm{mL})$, midazolam $(0.3 \mathrm{mg} / \mathrm{kg})$, and pancuronium $(0.5 \mathrm{mg} / \mathrm{kg})$ were added to the prime. Full bypass flow was set at $100 \mathrm{~mL} / \mathrm{kg} / \mathrm{min}$, and alpha-stat strategy was selected. CPB flow was maintained at $100 \mathrm{~mL} / \mathrm{kg} / \mathrm{min}$ except for the starting and the weaning of CPB in both groups. We did not correct the perfusion pressure because this CPB model followed a standard pediatric approach, which was a fixed-flow rate with no adjustment according to blood pressure. CPB was started, and the animals were perfused for 10 minutes at normothermic conditions $\left(37^{\circ} \mathrm{C}\right)$. Ventilation was stopped after the establishment of CPB. Animals were then cooled to a nasopharyngeal temperature of $28^{\circ} \mathrm{C}$ for 10 minutes according to the experimental protocol. Both groups underwent continuous $\mathrm{CPB}$ for 60 minutes at $28^{\circ} \mathrm{C}$. Before rewarming, methylprednisolone (30 $\mathrm{mg} / \mathrm{kg})$, furosemide $(0.25 \mathrm{mg} / \mathrm{kg})$, sodium bicarbonate $(10$ $\mathrm{mL})$, and mannitol $(0.5 \mathrm{~g} / \mathrm{kg})$ were administered into the pump. Animals were warmed to $37^{\circ} \mathrm{C}$ for 20 minutes. Ventilation was restarted 10 minutes before the weaning from $\mathrm{CPB}$ with an inspired oxygen fraction of 1.0. Animals were then weaned from $\mathrm{CPB}$, and the arterial and atrial cannulas were removed. Protamine $(5 \mathrm{mg} / \mathrm{kg}$ ) was administered intravenously after the animal was hemodynamically stable. Group L received fresh whole blood from a donor pig, drawn on the day of the surgery, immediately after the weaning from $\mathrm{CPB}$ as required to increase the hematocrit to $30 \%$. Minimum catecholamine was used at the time of weaning from $\mathrm{CPB}$.

\section{Postoperative Management}

Animals remained sedated and paralyzed. They were mechanically ventilated and monitored continuously for 6 hours after the operation, and the brain was fixed in situ with $4 \mathrm{~L}$ of $4 \%$ formaldehyde solution. The histologic outcomes were assessed.

\section{Data Collection}

Blood Gas Analyses

Arterial blood gas values, including electrolyte, glucose, and lactate concentrations, were measured at baseline, every 10 minutes during cooling and rewarming phase, every 30 minutes during moderate hypothermia, and every 60 minutes after weaning of CPB (i-STAT 300F; i-STAT Corporation, East Windsor, $\mathrm{NJ}$ ). Blood gas values are presented for an electrode temperature of $37^{\circ} \mathrm{C}$.

\section{Near-infrared Spectroscopy}

A pair of fiberoptic optodes was attached to the head of the animal with a probe holder after induction of anesthesia. The spacing of optodes was $4.0 \mathrm{~cm}$ in a coronal plane. These 2 optodes, a transmitter, and a receiver of laser light of near-infrared wavelength were connected to the NIRS (Niro300; Hamamatsu Photonics, Hamamatsu, Japan). This device calculates the relative concentration changes in oxygenated hemoglobin $\left(\mathrm{HbO}_{2}\right)$, deoxygenated hemoglobin 
TABLE 1. Comparison of preoperative conditions of the two groups*

\begin{tabular}{|c|c|c|c|}
\hline & Group H 30\% & Group L 15\% & $P$ valuet \\
\hline Body weight $(\mathrm{kg})$ & $8.7 \pm 0.6$ & $9.2 \pm 0.43$ & .49 \\
\hline $\mathrm{pH}$ & $7.51 \pm 0.04$ & $7.52 \pm 0.03$ & .72 \\
\hline $\mathrm{PacO}_{2}(\mathrm{~mm} \mathrm{Hg})$ & $42.7 \pm 3.1$ & $38.9 \pm 2.5$ & .35 \\
\hline $\mathrm{PaO}_{2}(\mathrm{~mm} \mathrm{Hg})$ & $242 \pm 26.4$ & $217 \pm 19.0$ & .46 \\
\hline Hematocrit $(\%)$ & $29.6 \pm 1.7$ & $30.7 \pm 1.3$ & .62 \\
\hline Osmolarity (m0sm/L) & $280.19 \pm 1.14$ & $282.93 \pm 1.74$ & .24 \\
\hline Lactate (mmol/L) & $1.78 \pm 0.70$ & $1.64 \pm 0.23$ & .84 \\
\hline Heart rate (beats/min) & $108.8 \pm 2.0$ & $110 \pm 4.9$ & .86 \\
\hline $\mathrm{MAP}(\mathrm{mm} \mathrm{Hg})$ & $67.8 \pm 2.92$ & $71.8 \pm 4.22$ & .47 \\
\hline $\mathrm{SvO}_{2}(\%)$ & $83.6 \pm 1.69$ & $85.2 \pm 1.25$ & .47 \\
\hline $\begin{array}{l}\text { Nasopharyngeal } \\
\text { temperature }\left({ }^{\circ} \mathrm{C}\right)\end{array}$ & $34.2 \pm 0.30$ & $34.0 \pm 0.44$ & .78 \\
\hline
\end{tabular}

$\mathrm{PaCO}_{2}$, Arterial partial pressure of carbon dioxide; $\mathrm{PaO}_{2}$, arterial partial pressure of oxygen; $\mathrm{MAP}$, mean arterial pressure; $\mathrm{SvO}_{2}$, venous oxygen saturation. *Mean \pm standard error; 5 piglets in group $\mathrm{H}, 6$ piglets in group L. †No significant differences were detected between the 2 groups according to the Student $t$ test.

$(\mathrm{HHb})$, and oxidized cytochrome $\mathrm{a}, \mathrm{a}_{3}\left(\mathrm{CytO}_{2}\right)$, as well as tissue oxygenation index (TOI), which is calculated from the ratio of oxygenated to total hemoglobin (HbT). Data were recorded every 10 seconds after the induction of anesthesia and for 6 hours after weaning from CPB.

\section{Histologic Assessment}

Histologic assessment was performed as previously described. ${ }^{3,4}$ Histologic damage was rated in 10 sites (frontal lobe, temporal lobe, occipital lobe, thalamus, caudate nucleus, hippocampus, dentate gyrus, midbrain, pons, and medulla oblongata) with the following categoric scale $(5=$ cavitated lesions with necrosis, $4=$ significant damage to neurons, $3=$ large clusters of injured neurons, $2=$ small clusters of damaged neurons, $1=$ isolated neuronal damage, $0=$ normal). Damage scores for all regions were summed and shown as the total histologic score. To avoid bias, all specimens were examined by 2 neuropathologists in a blinded fashion.

\section{Statistical Analysis}

All data were expressed in terms of the mean \pm standard error. The Student $t$ test was used to determine statistically significant differences between the 2 groups. Continuous data including hemodynamics and perfusion variables were compared between the 2 groups using repeated-measures of analysis of variance. Data were further compared by the Student $t$ test if the analysis of variance was significant. Histologic scores were compared by the Mann-Whitney $U$ test. Statistical analysis was performed using a statistical analysis software package (Stat-View version 5.0; Abacus Concepts, Berkeley, Calif).
TABLE 2. Changes in pH, arterial pressure of carbon dioxide, and arterial partial pressure of oxygen*

\begin{tabular}{|c|c|c|c|}
\hline & Group H 30\% & Group L 15\% & $P$ valuet \\
\hline \multicolumn{4}{|l|}{$\mathrm{pH}$} \\
\hline Before operation & $7.505 \pm 0.098$ & $7.523 \pm 0.067$ & .7174 \\
\hline On CPB & $7.509 \pm 0.029$ & $7.537 \pm 0.034$ & .1711 \\
\hline $\begin{array}{c}\text { End of CPB } \\
\text { cooling }\end{array}$ & $7.506 \pm 0.055$ & $7.490 \pm 0.047$ & .6313 \\
\hline $30 \mathrm{~min}$ & $7.507 \pm 0.064$ & $7.509 \pm 0.028$ & .9570 \\
\hline $60 \min$ & $7.523 \pm 0.069$ & $7.525 \pm 0.038$ & .9564 \\
\hline $\begin{array}{l}\text { End of CPB } \\
\text { rewarming }\end{array}$ & $7.604 \pm 0.073$ & $7.650 \pm 0.057$ & .2686 \\
\hline $1 \mathrm{~h}$ & $7.489 \pm 0.068$ & $7.544 \pm 0.084$ & .2725 \\
\hline $3 \mathrm{~h}$ & $7.470 \pm 0.025$ & $7.497 \pm 0.065$ & .4186 \\
\hline $6 \mathrm{~h}$ & $7.574 \pm 0.073$ & $7.555 \pm 0.067$ & .6618 \\
\hline \multicolumn{4}{|l|}{$\mathrm{PaCO}_{2}(\mathrm{~mm} \mathrm{Hg})$} \\
\hline Before operation & $42.70 \pm 6.88$ & $38.87 \pm 6.05$ & .3509 \\
\hline On CPB & $42.24 \pm 3.70$ & $37.47 \pm 5.40$ & .1293 \\
\hline $\begin{array}{c}\text { End of CPB } \\
\text { cooling }\end{array}$ & $43.02 \pm 4.09$ & $41.78 \pm 5.48$ & .6875 \\
\hline $30 \mathrm{~min}$ & $43.24 \pm 2.94$ & $41.03 \pm 2.40$ & .2025 \\
\hline $60 \mathrm{~min}$ & $40.56 \pm 3.38$ & $39.83 \pm 2.37$ & .6850 \\
\hline $\begin{array}{l}\text { End of } \mathrm{CPB} \\
\text { rewarming }\end{array}$ & $34.94 \pm 3.66$ & $34.28 \pm 3.67$ & .7739 \\
\hline $1 \mathrm{~h}$ & $40.06 \pm 3.89$ & $37.57 \pm 4.17$ & .3356 \\
\hline $3 \mathrm{~h}$ & $45.06 \pm 3.07$ & $40.15 \pm 4.52$ & .0699 \\
\hline $6 \mathrm{~h}$ & $38.38 \pm 3.26$ & $40.18 \pm 1.86$ & .2772 \\
\hline \multicolumn{4}{|l|}{$\mathrm{PaO}_{2}(\mathrm{~mm} \mathrm{Hg})$} \\
\hline Before operation & $242.00 \pm 59.06$ & $217.50 \pm 46.46$ & .4601 \\
\hline On CPB & $358.80 \pm 88.10$ & $444.67 \pm 52.41$ & .0753 \\
\hline $\begin{array}{c}\text { End of CPB } \\
\text { cooling }\end{array}$ & $608.80 \pm 38.03$ & $541.67 \pm 72.52$ & .0963 \\
\hline $30 \mathrm{~min}$ & $645.40 \pm 47.19$ & $594.83 \pm 27.05$ & .0649 \\
\hline $60 \mathrm{~min}$ & $649.20 \pm 42.25$ & $601.83 \pm 31.95$ & .0630 \\
\hline $\begin{array}{l}\text { End of } \mathrm{CPB} \\
\text { rewarming }\end{array}$ & $448.20 \pm 41.03$ & $451.33 \pm 75.92$ & .9362 \\
\hline $1 \mathrm{~h}$ & $303.40 \pm 91.12$ & $308.17 \pm 137.67$ & .9488 \\
\hline $3 \mathrm{~h}$ & $238.80 \pm 67.19$ & $240.50 \pm 85.53$ & .9720 \\
\hline $6 \mathrm{~h}$ & $254.80 \pm 21.21$ & $252.83 \pm 20.17$ & .8784 \\
\hline
\end{tabular}

$\mathrm{CPB}$, Cardiopulmonary bypass; $\mathrm{PaO}_{2}$, arterial oxygen tension; $\mathrm{PaCO}_{2}$, arterial partial pressure of carbon dioxide. $*>$ Mean \pm standard error; 5 piglets in group $\mathrm{H}, 6$ piglets in group L. $\dagger$ Student $t$ test detected differences.

\section{Results}

\section{Experimental Conditions}

There were no significant differences in baseline values between the 2 groups (Tables 1 and 2). During CPB, the hematocrit was significantly higher in group $\mathrm{H}$ relative to group L according to protocol (Table 3). Mean arterial pressure was significantly higher in group $\mathrm{H}$ compared with group L during the start of $\mathrm{CPB}$, during the cooling, and in the moderate hypothermia phase (Table 4). In the moderate hypothermia phase of $\mathrm{CPB}$, venous oxygen saturation was significantly higher in group $\mathrm{H}$ compared with group $\mathrm{L}$ (Table 5). 
TABLE 3. Changes in hematocrit, lactate, and osmolarity*

\begin{tabular}{|c|c|c|c|}
\hline & Group H 30\% & Group L 15\% & $P$ valuet \\
\hline \multicolumn{4}{|l|}{ Hematocrit (\%) } \\
\hline Before operation & $29.6 \pm 3.8$ & $30.7 \pm 3.1$ & .621 \\
\hline On CPB & $33.8 \pm 1.9$ & $14.7 \pm 3.4$ & $<.0001$ \\
\hline $\begin{array}{c}\text { End of CPB } \\
\text { cooling }\end{array}$ & $33.0 \pm 2.6$ & $12.7 \pm 2.9$ & $<.0001$ \\
\hline $30 \min$ & $33.0 \pm 2.3$ & $14.0 \pm 3.2$ & $<.0001$ \\
\hline $60 \min$ & $32.6 \pm 2.1$ & $15.0 \pm 3.3$ & $<.0001$ \\
\hline $\begin{array}{l}\text { End of } \mathrm{CPB} \\
\text { rewarming }\end{array}$ & $31.0 \pm 2.6$ & $17.0 \pm 2.9$ & $<.0001$ \\
\hline $1 \mathrm{~h}$ & $31.8 \pm 1.8$ & $28.8 \pm 4.6$ & .2119 \\
\hline $3 \mathrm{~h}$ & $31.0 \pm 4.6$ & $27.7 \pm 2.7$ & .1712 \\
\hline $6 \mathrm{~h}$ & $32.0 \pm 2.6$ & $33.5 \pm 3.9$ & .4837 \\
\hline \multicolumn{4}{|l|}{ Lactate (mmol/L) } \\
\hline Before operation & $1.78 \pm 1.57$ & $1.64 \pm 0.56$ & .8408 \\
\hline On CPB & $2.06 \pm 0.76$ & $2.31 \pm 2.00$ & .7984 \\
\hline $\begin{array}{c}\text { End of CPB } \\
\text { cooling }\end{array}$ & $3.03 \pm 1.12$ & $3.34 \pm 2.04$ & .7704 \\
\hline $30 \mathrm{~min}$ & $3.40 \pm 1.38$ & $3.43 \pm 1.75$ & .9761 \\
\hline $60 \mathrm{~min}$ & $3.84 \pm 1.47$ & $2.67 \pm 1.17$ & .1717 \\
\hline $\begin{array}{l}\text { End of CPB } \\
\text { rewarming }\end{array}$ & $3.88 \pm 1.29$ & $3.61 \pm 1.51$ & .7646 \\
\hline $1 \mathrm{~h}$ & $5.53 \pm 2.70$ & $6.35 \pm 1.44$ & .5358 \\
\hline $3 \mathrm{~h}$ & $2.49 \pm 1.08$ & $3.59 \pm 1.23$ & .1514 \\
\hline $6 \mathrm{~h}$ & $1.23 \pm 0.44$ & $1.83 \pm 0.99$ & .2491 \\
\hline \multicolumn{4}{|l|}{ Osmolarity (m0sm/L) } \\
\hline Before operation & $280.19 \pm 2.54$ & $282.93 \pm 4.27$ & .2415 \\
\hline On CPB & $284.74 \pm 2.43$ & $286.34 \pm 3.85$ & .4449 \\
\hline $\begin{array}{c}\text { End of CPB } \\
\text { cooling }\end{array}$ & $288.56 \pm 3.89$ & $288.80 \pm 4.16$ & .9238 \\
\hline $30 \mathrm{~min}$ & $290.72 \pm 2.38$ & $290.29 \pm 5.06$ & .8651 \\
\hline $60 \min$ & $291.94 \pm 1.84$ & $290.89 \pm 3.39$ & .5500 \\
\hline $\begin{array}{l}\text { End of CPB } \\
\text { rewarming }\end{array}$ & $288.10 \pm 3.12$ & $289.85 \pm 4.26$ & .4648 \\
\hline $1 \mathrm{~h}$ & $290.39 \pm 3.16$ & $289.61 \pm 3.75$ & .7211 \\
\hline $3 \mathrm{~h}$ & $285.33 \pm 2.28$ & $285.30 \pm 3.16$ & .9927 \\
\hline $6 \mathrm{~h}$ & $286.58 \pm 2.20$ & $286.13 \pm 2.99$ & .7854 \\
\hline
\end{tabular}

$C P B$, Cardiopulmonary bypass. *Mean \pm standard error; 5 piglets in group $\mathrm{H}, 6$ piglets in group $\mathrm{L}$. $\dagger$ Student $t$ test detected differences.

\section{Operative Results}

One animal in group $\mathrm{L}$ demonstrated severe hypoxia after the weaning from CPB. All data in this animal were excluded from the analysis.

\section{Near-infrared Spectroscopy}

The $\mathrm{HbO}_{2}$ signal in group $\mathrm{H}$ slightly increased after initiating $\mathrm{CPB}$ and remained at the same level during both the normothermic and moderate hypothermic phases. It gradually decreased during the rewarming phase. On the other hand, the $\mathrm{HbO}_{2}$ signal in group $\mathrm{L}$ decreased and remained low throughout the $\mathrm{CPB}$. After the weaning from $\mathrm{CPB}$, this signal increased and reached baseline value. The $\mathrm{HbO}_{2}$ signal was significantly lower in group $\mathrm{L}$ compared with group $\mathrm{H}$ during
TABLE 4. Changes in heart rate and mean arterial pressure*

\begin{tabular}{|c|c|c|c|}
\hline & Group H 30\% & Group L 15\% & $P$ valuet \\
\hline \multicolumn{4}{|l|}{ Heart rate (beats/min) } \\
\hline Before operation & $108.8 \pm 4.4$ & $109.8 \pm 12.1$ & .8614 \\
\hline On CPB & $130.2 \pm 19.5$ & $133.0 \pm 20.2$ & .8216 \\
\hline End of CPB cooling & $93.0 \pm 9.0$ & $95.3 \pm 15.0$ & .7684 \\
\hline $30 \mathrm{~min}$ & $91.2 \pm 11.1$ & $98.7 \pm 14.9$ & .3786 \\
\hline $60 \mathrm{~min}$ & $92.4 \pm 12.8$ & $97.5 \pm 15.4$ & .5698 \\
\hline $\begin{array}{l}\text { End of CPB } \\
\text { rewarming }\end{array}$ & $186.2 \pm 9.5$ & $164.8 \pm 14.5$ & .0203 \\
\hline $1 \mathrm{~h}$ & $115.0 \pm 23.5$ & $131.8 \pm 22.5$ & .2566 \\
\hline $3 \mathrm{~h}$ & $109.0 \pm 19.7$ & $100.7 \pm 9.5$ & .3806 \\
\hline $6 \mathrm{~h}$ & $115.8 \pm 6.2$ & $107.7 \pm 6.6$ & .0675 \\
\hline \multicolumn{4}{|l|}{$\mathrm{MAP}(\mathrm{mm} \mathrm{Hg})$} \\
\hline Before operation & $67.8 \pm 6.5$ & $71.8 \pm 10.3$ & .4711 \\
\hline On CPB & $74.0 \pm 2.6$ & $47.7 \pm 6.9$ & $<.0001$ \\
\hline End of CPB cooling & $75.2 \pm 2.7$ & $51.5 \pm 3.9$ & $<.0001$ \\
\hline $30 \mathrm{~min}$ & $75.8 \pm 2.6$ & $54.0 \pm 2.4$ & $<.0001$ \\
\hline $60 \mathrm{~min}$ & $76.0 \pm 3.1$ & $55.2 \pm 2.4$ & $<.0001$ \\
\hline $\begin{array}{l}\text { End of CPB } \\
\text { rewarming }\end{array}$ & $71.2 \pm 5.4$ & $67.5 \pm 14.4$ & .6029 \\
\hline $1 \mathrm{~h}$ & $73.0 \pm 3.4$ & $75.7 \pm 8.1$ & .5124 \\
\hline $3 \mathrm{~h}$ & $80.0 \pm 2.9$ & $83.8 \pm 7.9$ & .3318 \\
\hline $6 \mathrm{~h}$ & $85.8 \pm 13.6$ & $93.3 \pm 8.2$ & .2838 \\
\hline
\end{tabular}

$C P B$, Cardiopulmonary bypass; MAP, mean arterial pressure. *Mean \pm standard error; 5 piglets in group $\mathrm{H}, 6$ piglets in group $\mathrm{L}$. $†$ Student $t$ test detected differences.

CPB $(P<.0001)$. No significant difference was observed between the 2 groups after the weaning from $\mathrm{CPB}$. The $\mathrm{HHb}$ signal in group $\mathrm{H}$ increased after initiating $\mathrm{CPB}$ and remained at the same level throughout $\mathrm{CPB}$, whereas it remained at baseline value in group $\mathrm{L}$. The signal in group $\mathrm{H}$ was significantly higher than that in group L during CPB $(P<.0001)$. There was no significant difference between the 2 groups after $\mathrm{CPB}$. The HbT signal showed almost the same pattern as the $\mathrm{HbO}_{2}$ signal. The $\mathrm{HbT}$ signal was significantly lower in group $\mathrm{L}$ compared with group $\mathrm{H}$ during $\mathrm{CPB}(P<.0001)$. No significant difference was observed between the 2 groups after weaning from $\mathrm{CPB}$. The $\mathrm{CytO}_{2}$ signal remained at baseline value throughout $\mathrm{CPB}$ in group $\mathrm{H}$. On the other hand, the signal in group $\mathrm{L}$ decreased after starting $\mathrm{CPB}$ and showed a significant difference throughout $\mathrm{CPB}$ compared with group $\mathrm{H}$ $(P<.0001)$. There was no significant difference in TOI between the 2 groups $(P=.0705)$. Some animals in both groups showed values of less than $50 \%$ during the rewarming phase (Figure 1).

\section{Histologic Assessment}

In group $\mathrm{H}$, histologic damage was found in 2 sites (frontal lobe and thalamus). On the other hand, almost all the sites except for the dentate gyrus and brain stem showed histologic damage in group L. There were significant differences 
TABLE 5. Changes in venous oxygen saturation and nasopharyngeal temperature*

\begin{tabular}{llll}
\hline & Group H 30\% & Group L 15\% & $\boldsymbol{P}$ valuet \\
\hline $\mathrm{SvO}_{2}(\%)$ & & & \\
Before operation & $83.60 \pm 3.78$ & $85.17 \pm 3.06$ & .4661 \\
On CPB & $88.20 \pm 9.23$ & $81.67 \pm 9.75$ & .2865 \\
End of CPB cooling & $91.80 \pm 1.10$ & $87.67 \pm 1.75$ & .0014 \\
30 min & $93.40 \pm 1.82$ & $89.33 \pm 2.50$ & .0145 \\
60 min & $93.80 \pm 1.30$ & $90.83 \pm 2.23$ & .0281 \\
End of CPB rewarming & $83.80 \pm 8.23$ & $78.17 \pm 4.58$ & .1837 \\
1 h & $79.80 \pm 5.02$ & $77.67 \pm 14.4$ & .7606 \\
3 h & $76.20 \pm 5.76$ & $79.00 \pm 6.51$ & .4741 \\
6 h & $83.80 \pm 6.22$ & $80.17 \pm 8.93$ & .4638 \\
Nasopharyngeal & & & \\
temperature ( ${ }^{\circ}$ C) & & & \\
Before operation & $34.16 \pm 0.67$ & $34.00 \pm 1.07$ & .7792 \\
On CPB & $36.04 \pm 0.43$ & $35.68 \pm 0.83$ & .4088 \\
End of CPB cooling & $28.26 \pm 0.68$ & $27.90 \pm 0.73$ & .4248 \\
30 min & $27.92 \pm 0.39$ & $27.90 \pm 0.42$ & .9370 \\
60 min & $27.86 \pm 0.34$ & $27.83 \pm 0.46$ & .9166 \\
End of CPB rewarming & $36.58 \pm 0.81$ & $36.87 \pm 0.65$ & .5297 \\
$1 \mathrm{~h}$ & $34.24 \pm 0.57$ & $34.13 \pm 0.83$ & .8138 \\
3 h & $35.28 \pm 1.01$ & $35.02 \pm 0.91$ & .6731 \\
6 h & $35.50 \pm 1.09$ & $35.48 \pm 1.09$ & .9804 \\
\hline
\end{tabular}

$\mathrm{CPB}$, Cardiopulmonary bypass; $\mathrm{SvO}_{2}$, venous oxygen saturation. *Mean \pm standard error; 5 piglets in group $\mathrm{H}, 6$ piglets in group L. † Student $t$ test detected differences.

in the hippocampus $(P=.0061)$ and total histologic score $(P=.0071)$ between the groups (Figure 2).

\section{Discussion}

The current study demonstrated that there is a higher risk of neurologic injury caused by low hematocrit during and after moderate hypothermic CPB without circulatory arrest. A low hematocrit of less than $15 \%$ is dangerous and should be avoided in pediatric cardiac surgery.

It has been controversial whether a hematocrit as high as $30 \%$ is necessary during CPB. The previous study states that a hematocrit of $15 \%$ to $20 \%$ is safe during CPB. ${ }^{5}$ In addition, it has been believed that a higher hematocrit under hypothermia results in slugging of red blood cells and can lead to inappropriate microcirculation. Recently, Dr. Jonas's group from Children's Hospital Boston reported that a hematocrit of $30 \%$ was better than $20 \%$ after CPB with deep hypothermic circulatory arrest in an experimental study ${ }^{4,6,7}$ and a randomized clinical trial. ${ }^{1}$ Habib and colleagues ${ }^{2}$ reported that a low hematocrit of less than $22 \%$ could lead to a higher possibility of multiple organ failure in 5000 adult patients with cardiac disease. However, these studies were performed in pediatric patients with hypothermic CPB consisting of circulatory arrest or reduced flow bypass at deep hypothermia or in adult patients with atherosclerosis. Therefore, there has been no evidence regarding optimal and safe hematocrit during CPB without circulatory arrest and reduced flow at deep hypothermia in pediatric patients. The present study is the first to address this issue.

Histologic assessment should be considered the most reliable examination for brain ischemic damage. In the current study, damage in the frontal lobe and thalamus was seen in both groups. CPB itself may be a risk for cerebral ischemic damage. In general, the hippocampus is a more vulnerable region for ischemia. Group L revealed significantly poorer scores in the hippocampus compared with group $\mathrm{H}$. This result suggests that straight hemodilution producing a hematocrit of less than $15 \%$ is associated with a higher risk of brain injury. A significant difference in the total histologic score strongly supports this hypothesis. In the meantime, we have performed histologic assessments of brain specimens that were fixed in situ at 6 hours after weaning from CPB. In a previous study it was demonstrated that ischemic cell death began as early as 6 hours after hypothermic circulatory arrest, reached its peak at 72 hours, and continued for at least 7 days. $^{8}$ In the current study, the histologic score was significantly worse in group L compared with group $\mathrm{H}$ at 6 hours after $\mathrm{CPB}$. If a specimen was fixed at 72 hours after $\mathrm{CPB}$ in the current study, it might be possible that the histologic score in group L may show more severe damage. In the future, we plan to perform a survival study including neurologic and behavioral evaluations, and histologic assessment of apoptosis induced by hemodilution. The future survival study could further elucidate the risk of hemodilution under $\mathrm{CPB}$.

There was no significant difference in lactate between the 2 groups. The changes in lactate showed almost the same pattern between the groups. During CPB, lactate concentration was 3.0 $\mathrm{mmol} / \mathrm{L}$ something in both groups, and the highest level was $5.53 \pm 2.70 \mathrm{mmol} / \mathrm{L}$ in group $\mathrm{H}$ and $6.35 \pm 1.44 \mathrm{mmol} / \mathrm{L}$ in group $\mathrm{L}$ at 1 hour after the operation. The levels had declined gradually and returned to the prebypass value 6 hours after the operation (Table 3). We speculated that there might not be significant circulatory failure, such as longer deep hypothermia and circulatory arrest even in group L. On the other hand, on the basis of the histology results in group L, we believe that the nadir hematocrit of $15 \%$ caused a disorder of tissue oxygenation leading to mild cerebral damages, not severe damages. However, the influence on the whole body was within limits, and there was no significant difference in lactate, which was derived from the systemic line, not the sagittal sinus.

NIRS $^{9,10}$ has been recently used in cardiac surgery, and its use has been reported in both laboratory ${ }^{11}$ and clinical studies. ${ }^{12,13} \mathrm{HbO}_{2}, \mathrm{HHb}, \mathrm{HbT}$, and $\mathrm{CytO}_{2}$ signals detected by NIRS show the relative concentration changes of the baseline value, and the TOI reveals the tissue oxygenation that is derived from different parameters than the abovementioned 4 parameters. ${ }^{14}$ In the current study, the NIRS device revealed a significantly higher value of $\mathrm{HbO}_{2}$ and 


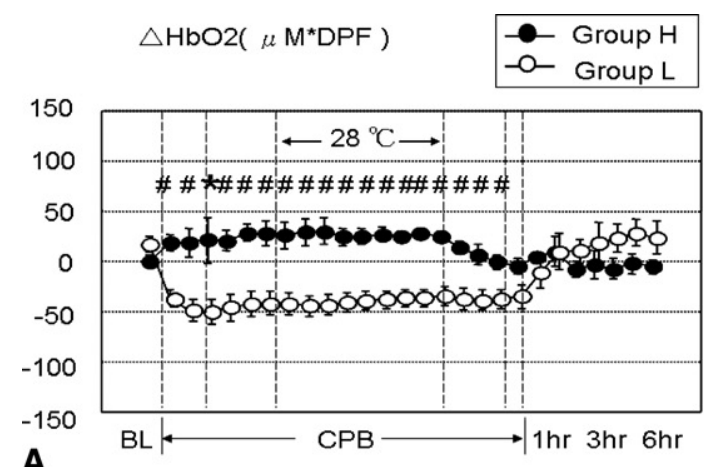

$\triangle \mathrm{HbT}\left(\mu \mathrm{M}{ }^{*} \mathrm{DPF}\right)$

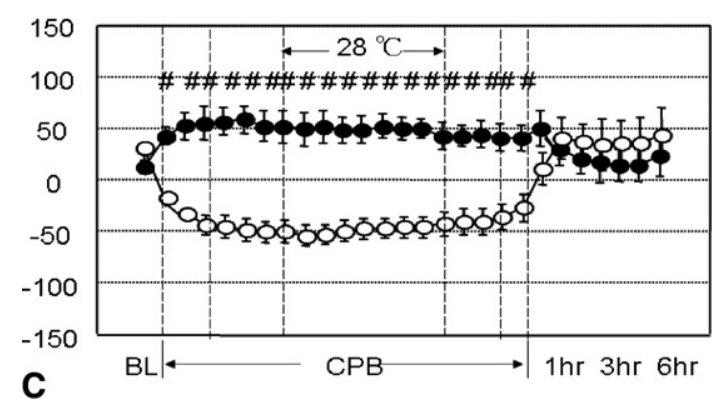

TOI ( \% )

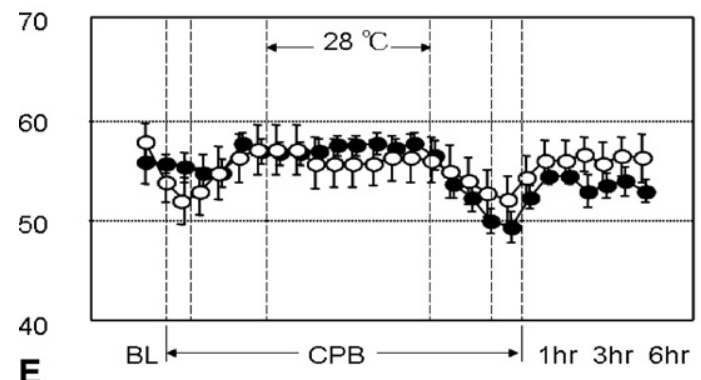

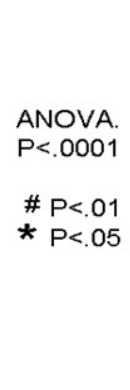

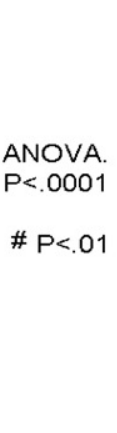

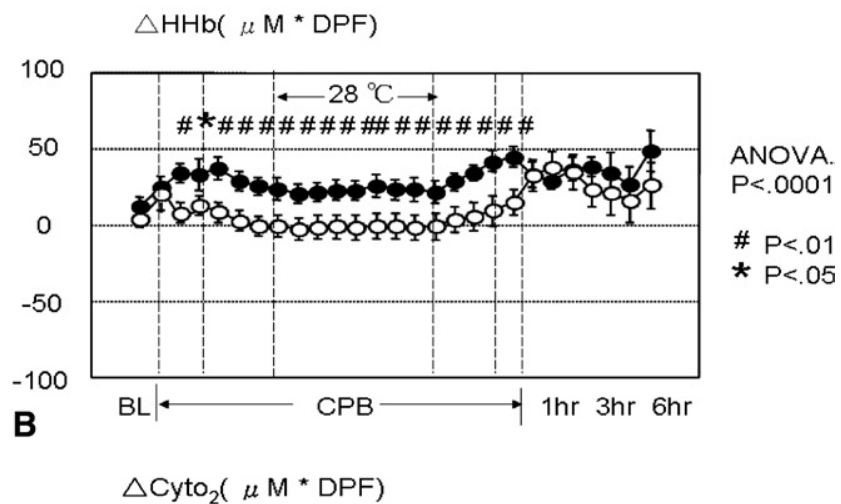

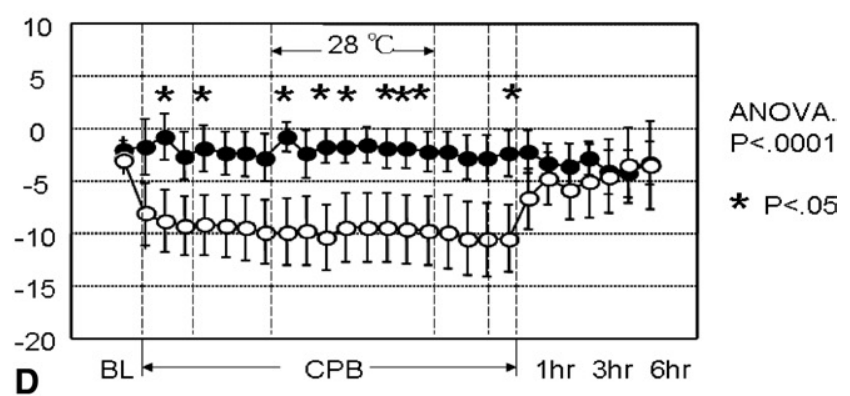

ANOVA. $P=.0705$

Figure 1. Changes in NIRS data. $\mathrm{A}, \mathrm{HbO}_{2}$ signal. $\mathrm{B}, \mathrm{HHb}$ signal. $\mathrm{C}, \mathrm{HbT}$ signal. D, CytO $\mathrm{O}_{2}$ signal. $\mathrm{E}, \mathrm{TOI}$. ANOVA,

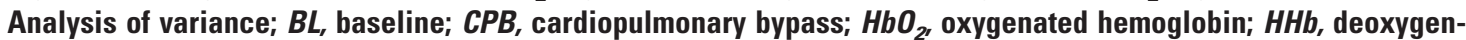
ated hemoglobin; $\mathrm{HbT}$, total hemoglobin; $\mathrm{CytO}_{2}$, oxidized cytochrome a, $\mathrm{a}_{3}$; TOI, tissue oxygenation index; DPF, differential pathlength factor.

$\mathrm{HbT}$ in group $\mathrm{H}$ than in group $\mathrm{L}$. The hematocrit in group $\mathrm{H}$ was approximately $33 \%$, which was higher than the baseline value, whereas group L showed a low hematocrit of $10 \%$ to $15 \%$. Differences of hematocrit could affect the $\mathrm{HbO}_{2}$ and $\mathrm{HbT}$ values, and therefore this significant difference may not be important. Precisely, there was an increase of approximately $4 \%$ in hematocrit after initiating CPB in group $\mathrm{H}$. This $4 \%$ increase may produce a higher level of $\mathrm{HbO}_{2}$ and $\mathrm{HbT}$ signals in group $\mathrm{H}$. On the other hand, the $\mathrm{HHb}$ value in group $\mathrm{L}$ remained at baseline level after initiating $\mathrm{CPB}$ when the hematocrit level was lower than the baseline value. The increase in $\mathrm{HHb}$ in group $\mathrm{H}$ also can be ex- plained by the $4 \%$ increase in hematocrit. However, the $\mathrm{HHb}$ value in group $\mathrm{L}$ remained at baseline level after initiation of CPB, although the hematocrit level was lower than the baseline value. In general, when a cell is using enough oxygen, absolute deoxyhemoglobin value is theoretically almost zero. If zero value of the absolute deoxyhemoglobin is kept during CPB in group L, the $\mathrm{HHb}$ signal should be significantly lower than the baseline level because the hematocrit is almost half of the preoperative value. However, the result was different and the $\mathrm{HHb}$ signal remained at baseline level in group L. This indicates that the actual deoxyhemoglobin value (the absolute value) in- 


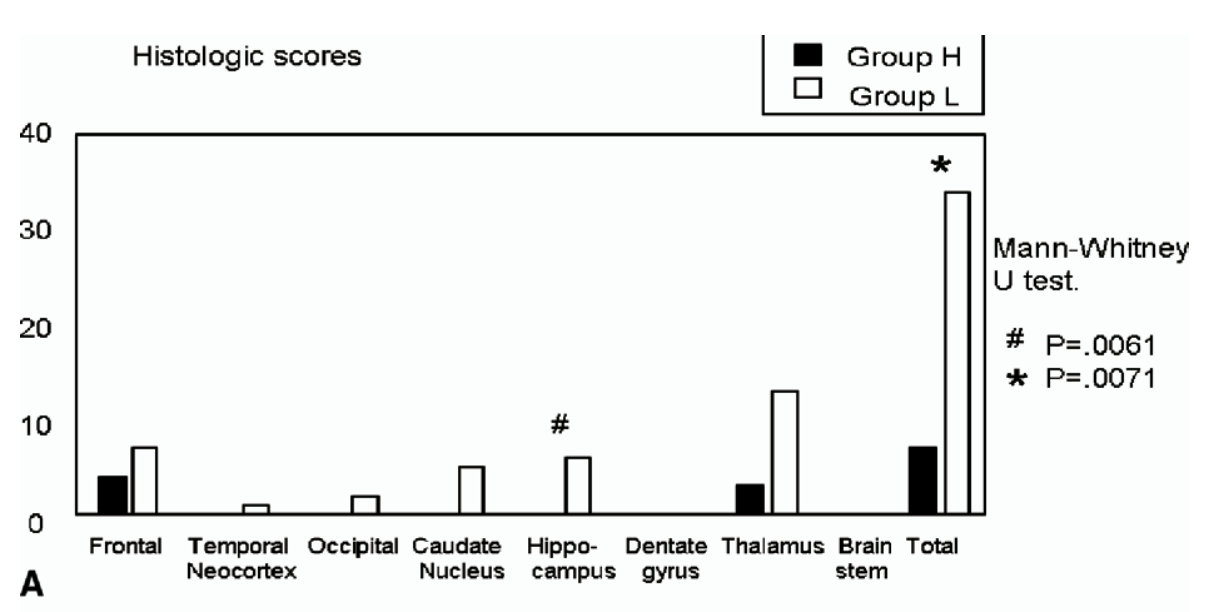

\section{Histology}

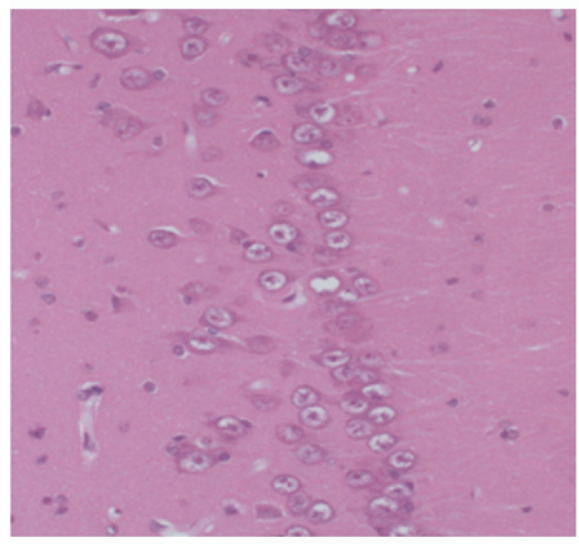

a. Grade 0

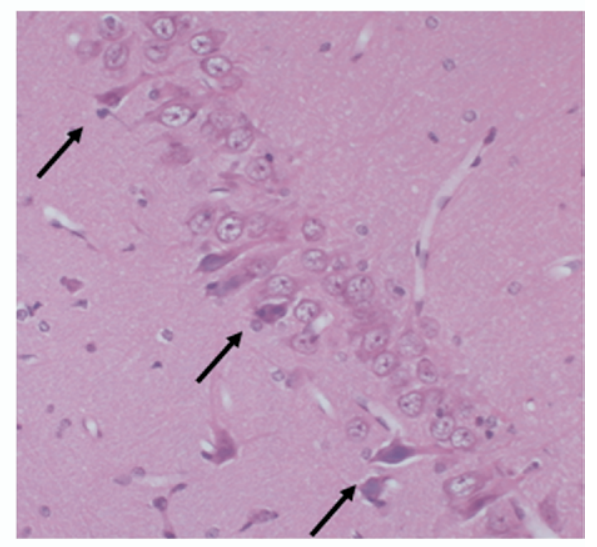

b. Grade 3
Figure 2. A, Results of histologic scores. Mann-Whitney $\boldsymbol{U}$ test revealed differences in hippocampus and total histologic score. B, Histology from hippocampus, paraffin section, hematoxylin-eosin stain. a. Grade 0 , showing no damage from group $\mathrm{H}(\times 20)$. b. Grade 3 , showing hypoxic-ischemic injury from group $L(\times 20)$. This is the most severely injured animal in this group. This would be scored as having a $3+$ lesion. Note several neurons with hypereosinophilic cytoplasm and karyorrhectic nuclei (arrows). creased after initiating $\mathrm{CPB}$, suggesting that there was an increase in oxygen consumption. Therefore, CPB might lead to a lower oxygen condition in group $\mathrm{L}$ even during moderate hypothermia. This hypothesis is supported by the results of neuropathology in which the total histologic score in group $\mathrm{L}$ is worse than that in group H. On the other hand, in the current study, there was no significant difference in TOI between the 2 groups, although there were significant changes in the hematocrit level. However, some animals in each group showed a TOI of less than $50 \%$ during the rewarming phase, and neuropathology in the frontal lobe showed damages in both groups. Seven animals showed histologic damage in the frontal lobe: 3 in group $\mathrm{H}$ and 4 in group L. Among these, 5 piglets revealed a TOI of less than $50 \%$. This is consistent with the previous report from Hagino and colleagues ${ }^{15}$ that a TOI of less than $55 \%$ is a strong predictor of neurologic injury. The NIRS device measures the tissue oxygenation of only the frontal lobe region. Therefore, a TOI of less than $50 \%$ might be associated with brain damage in selected regions (frontal lobe), and there might be a consistency between the NIRS data and neuropathology. The difference between the total histologic score and TOI data may be explained by the above reasons. The alpha-stat strategy used in the current study may affect this result. The use of $\mathrm{pH}$-stat strategy could avoid brain damage occurring in some regions even under the high hematocrit in group H. ${ }^{11,16}$ From this observation, we infer that it may be prudent to estimate the critical cerebral oxygenation during $\mathrm{CPB}$ with other parameters such as absolute cytochrome signal. ${ }^{17,18}$ Future studies are required to establish the absolute signal for detecting brain ischemia and the limits of safety of hematocrit during CPB. ${ }^{19}$ Nonetheless, cardiac surgeons should note that excessive hemodilution may have a higher incidence of postoperative neurologic damage even if there is no circulatory arrest. In addition, prospective, randomized clinical trials in combination with real-time monitoring should be planned to resolve this issue. ${ }^{20,21}$

\section{Limitations}

There are 3 limitations to the current study: the effect of blood transfusion, the timing of blood transfusion, and the 
perfusion pressure during CPB. Recently, Habib and colleagues $^{22}$ reported that stored red blood cell transfusion during CPB increased the incidence of postoperative renal injury and hospital stays in adult patients undergoing isolated coronary artery bypass grafting. Also, Tsai and colleagues $^{23}$ showed that transfusion with stored red blood cells in a normovolemic anemic condition caused more malperfused and underoxygenated microvasculature that was not detectable at the systemic level compared with fresh whole-blood transfusion in an experimental study. In the current study, we used fresh whole blood from a donor piglet. It is unclear whether fresh whole blood has an influence on microvasculature in the brain. In regard to the timing of blood transfusion, there might be some difference in inflammation response. In the current study, group $\mathrm{H}$ was transfused at the start of CPB and group L was transfused after weaning from CPB. This might be associated with the difference in inflammatory response in the current study. Finally, this CPB model is a standard pediatric approach and reflects standard clinical practice. Therefore, the perfusion pressure was significantly lower in group L compared with group $\mathrm{H}$ during $\mathrm{CPB}$ because of a direct effect of viscosity secondary to lower hematocrit. The perfusion pressure is also important in oxygen delivery to the brain. In the current study, the perfusion pressure in group $\mathrm{L}$ was maintained at a mean arterial pressure of $50 \mathrm{~mm} \mathrm{Hg}$ to $55 \mathrm{~mm} \mathrm{Hg}$ during CPB. Therefore, there may be less correlation between the histologic score and perfusion pressure. The hematocrit during CPB may play a large part in brain oxygenation.

We thank Shunji Kawamura, MD, for histologic assessment, and Yusuke Iwata, MD, Yoshimichi Kosaka, MD, Kazuma Maisawa, MD, and Koichi Sughimoto, MD, for technical support. Katsunori Shimada, $\mathrm{PhD}$, provided us valuable advice regarding the statistical analysis. This study was performed at Terumo Medical Pranex, Kanagawa, Japan. We also thank Makoto Takahashi, DVM for his technical support. We also appreciate Terumo Corporation, Tokyo, Japan for their support.

\section{References}

1. Jonas RA, Wypij D, Roth SJ, Bellinger DC, Visconti KJ, du Plessis $\mathrm{AJ}$, et al. The influence of hemodilution on outcome after hypothermic cardiopulmonary bypass: results of a randomized trial in infants. J Thorac Cardiovasc Surg. 2003;126:1765-74.

2. Habib RH, Zacharias A, Schwann TA, Riordan CJ, Durham SJ, Shah A. Adverse effects of low hematocrit during cardiopulmonary bypass in the adult: should current practice be changed? J Thorac Cardiovasc Surg. 2003;125:1438-50.

3. Miura T, Laussen P, Lidov HG, DuPlessis A, Shin'oka T, Jonas RA. Intermittent whole-body perfusion with "somatoplegia" versus blood perfusate to extend duration of circulatory arrest. Circulation. 1996; 94(9 Suppl):II56-62

4. Shin'oka T, Shum-Tim D, Jonas RA, Lidov HG, Laussen PC, Miura T, et al. Higher hematocrit improves cerebral outcome after deep hypothermic circulatory arrest. J Thorac Cardiovasc Surg. 1996; 112:1610-20.
5. Hammon JW, Stump DA, Butterworth JB, Moody DM. Approaches to reduce neurologic complications during cardiac surgery. Semin Thorac Cardiovasc Surg. 2001;13:184-91.

6. Sakamoto T, Jonas RA, Hatsuoka S, Stock UA, Duebener LF, Lidov $\mathrm{HG}$, et al. Prediction of safe duration of hypothermic circulatory arrest by near-infrared spectroscopy. J Thorac Cardiovasc Surg. 2001;122: 339-50.

7. Sakamoto T, Jonas RA, Zurakowski D, Duebener LF, Lidov HG, Holmes GL, et al. Interaction of temperature with hematocrit level and $\mathrm{pH}$ determines safe duration of hypothermic circulatory arrest. $J$ Thorac Cardiovasc Surg. 2004;128:220-32.

8. Hagl C, Tatton NA, Khaladj N, Zhang N, Nandor S, Insolia S, et al. Involvement of apoptosis in neurological injury after hypothermic circulatory arrest: a new target for therapeutic intervention? Ann Thorac Surg. 2001;72:1457-64.

9. Jobsis FF. Noninvasive, infrared monitoring of cerebral and myocardial oxygen sufficiency and circulatory parameters. Science. 1977;198: 1264-7.

10. Wahr JA, Tremper KK, Samra S, Delpy DT. Near-infrared spectroscopy: theory and applications. J Cardiothorac Vasc Anesth. 1996;10: 406-18.

11. Nomura F, Naruse H, duPlessis A, Hiramatsu T, Forbess J, Holtzman $\mathrm{D}$, et al. Cerebral oxygenation measured by near infrared spectroscopy during cardiopulmonary bypass and deep hypothermic circulatory arrest in piglets. Pediatr Res. 1996;40:790-6.

12. Nollert G, Mohnle P, Tassani-Prell P, Uttner I, Borasio GD, Schmoeckel M, et al. Postoperative neuropsychological dysfunction and cerebral oxygenation during cardiac surgery. Thorac Cardiovasc Surg. $1995 ; 43: 260-4$.

13. Sakamoto T, Kurosawa H, Shin'oka T, Aoki M, Isomatsu Y. The influence of $\mathrm{pH}$ strategy on cerebral and collateral circulation during hypothermic cardiopulmonary bypass in cyanotic patients with heart disease: results of a randomized trial and real-time monitoring. $J$ Thorac Cardiovasc Surg. 2004;127:12-9.

14. Suzuki S, Takasaki S, Ozaki T, Kobayashi Y. Tissue oxygenation monitor using NIR spatially resolved spectroscopy. Proc SPIE. 1999; 3597:582-92

15. Hagino I, Anttila V, Zurakowski D, Duebener LF, Lidov HG, Jonas RA. Tissue oxygenation index is a useful monitor of histologic and neurologic outcome after cardiopulmonary bypass in piglets. J Thorac Cardiovasc Surg. 2005;130:384-92.

16. Kurth CD, O'Rourke MM, O'Hara IB. Comparison of pH-stat and alpha-stat cardiopulmonary bypass on cerebral oxygenation and blood flow in relation to hypothermic circulatory arrest in piglets. Anesthesiology. 1998;89:110-8.

17. Sakamoto T, Jonas RA, Stock UA, Hatsuoka S, Cope M, Springett RJ, et al. Utility and limitations of near-infrared spectroscopy during cardiopulmonary bypass in a piglet model. Pediatr Res. 2001;49:770-6.

18. Ferrari M, Mottola L, Quaresima V. Principles, techniques, and limitations of near infrared spectroscopy. Can J Appl Physiol. 2004;29: 463-87.

19. Kawashima Y, Yamamoto Z, Manabe H. Safe limits of hemodilution in cardiopulmonary bypass. Surgery. 1974;76:391-7.

20. Bellinger DC, Wypij D, Kuban KC, Rappaport LA, Hickey PR, Wernovsky G, et al. Developmental and neurological status of children at 4 years of age after heart surgery with hypothermic circulatory arrest or low-flow cardiopulmonary bypass. Circulation. 1999;100:526-32.

21. Bellinger DC, Wypij D, du Plessis AJ, Rappaport LA, Jonas RA, Wernovsky G, et al. Neurodevelopmental status at eight years in children with dextro-transposition of the great arteries: the Boston Circulatory Arrest Trial. J Thorac Cardiovasc Surg. 2003;126:1385-96.

22. Habib RH, Zacharias A, Schwann TA, Riordan CJ, Engoren M, Durham SJ, et al. Role of hemodilutional anemia and transfusion during cardiopulmonary bypass in renal injury after coronary revascularization: implications on operative outcome. Crit Care Med. 2005; 33:1749-56.

23. Tsai AG, Cabrales P, Intaglietta M. Microvascular perfusion upon exchange transfusion with stored red blood cells in normovolemic anemic conditions. Transfusion. 2004;44:1626-3. 